\title{
Trajectory and determinants of change in lean soft tissue over the postpartum period
}

\author{
Sarah A. Elliott, Leticia C. R. Pereira, Linda J. McCargar, Carla M. Prado, Rhonda C. Bell* and the ENRICH \\ Study Team \\ Department of Agricultural, Food and Nutritional Science, University of Alberta, Edmonton, AB, T6G 2E1, Canada
}

(Submitted 24 August 2017 - Final revision received 22 May 2018 - Accepted 5 July 2018 - First published online O4 September 2018)

\begin{abstract}
The aim of this study was to characterise changes in lean soft tissue (LST) and examine the contributions of energy intake, physical activity and breast-feeding practices to LST changes at 3 and 9 months postpartum. We examined current weight, LST (via dual-energy X-ray absorptiometry), dietary intake (3-d food diary), physical activity (Baecke questionnaire) and breast-feeding practices (3-d breast-feeding diary) in forty-nine women aged 32.9 (sD 3.8) years. Changes in LST varied from -2.51 to $+2.50 \mathrm{~kg}$ with twenty-nine women gaining LST (1.1 (sD 0.7$) \mathrm{kg}, P<0.001)$ and twenty women losing LST (-0.9 (sD 0.8$) \mathrm{kg}, P<0.001)$. Energy intake (133 (sD 42$) v .109$ (sD 33$) \mathrm{kJ} / \mathrm{kg}, P=0.019)$ and $\% \mathrm{~kJ}$ from fat at 3 months postpartum was higher in women who gained LST at 9 months postpartum (gained LST = 34 (sD 5) \% kJ; lost $\mathrm{LST}=29(\mathrm{sD} 4) \% \mathrm{~kJ}, P=0.002$ ). Women who gained LST reported breast-feeding their infants more frequently (gained LST $=8$ (sD 3 ) feeds/d; lost LST $=5$ (sD 1) feeds/d, $P=0 \cdot 014$ ) and for more time per d (gained LST=115 (sD 78) $\mathrm{min} / \mathrm{d}$; lost LST =59 (sD 34) $\mathrm{min} / \mathrm{d}, P=0 \cdot 016$ ) at 9 months postpartum. Energy intake and $\% \mathrm{~kJ}$ from fat at 3 months were significant predictors of LST gain $(\beta=0 \cdot 08$ (SE 0.04) and 0.24 (SE 0.09), respectively). This suggests that gain in LST may be associated with more frequent and longer episodes of breast-feeding at 9 months postpartum as well as dietary intake early in the postpartum period.
\end{abstract}

Key words: Postpartum period: Lean soft tissue: Lactation: Dietary intake: Physical activity

Pregnancy is now an independent risk factor for obesity in women due to excess gestational weight gained (GWG) and subsequently retained throughout the postpartum period. While weight retention and efforts to reduce excess weight in the postpartum period have been widely reported, little attention has been paid to the composition of the retained weight. The relative composition of the retained weight is important, as changes in fat mass (FM) and lean soft tissue (LST) throughout the postpartum period may be a predictor of metabolic health complications later in life ${ }^{(1)}$. The health consequences related to FM retention in the postpartum period such as increased BMI, and risk for glucose intolerance and insulin resistance are now well established ${ }^{(1)}$. However, limited research has documented changes in LST over the postpartum period and how this body composition component may influence maternal health over the pregnancy-postpartum cycle.

Despite it being well established that changes in body composition are not always reflected in weight change, literature in this area primarily focusses on changes in postpartum weight and BMI. In addition, changes in FM and LST are now considered better predictors of maternal nutritional status ${ }^{(2)}$ yet few studies have evaluated these changes, and those that have, offer contradictory evidence. Research to date has focussed mainly on changes in FM with some studies reporting a significant decline in $\mathrm{FM}^{(3)}$ early in the postpartum period; in contrast, other studies have documented no changes in $\mathrm{FM}^{(4)}$. Of note, the majority of studies reviewed by Neville et al $^{(5)}$ reported little or no association between lactation and change in FM in healthy, well-nourished women. This questions the relevance of investigations which focus on FM alone and emphasises the need to explore changes in other components of maternal body composition.

The trajectory of LST over the postpartum period has largely been ignored, despite the importance of this body composition component to support health across the lifespan in the immediate and long term being recently highlighted ${ }^{(6,7)}$. In the short term, losses in LST can contribute to the development of obesity via a reduction in energy metabolism ${ }^{(8)}$. For women in childbearing years, this pattern of body composition change could perpetuate the development of obesity in subsequent pregnancies resulting in unfavourable body composition (concurrent low LST and high FM) tracking into the postpartum period $^{(4)}$. Women's long-term health can also be impacted, as heading towards menopause with already depleted levels of

Abbreviations: DXA, dual-energy X-ray absorptiometry; FFM, fat-free mass; FM, fat mass; GWG, gestational weight gain; LST, lean soft tissue.

* Corresponding author: R. C. Bell, email rhonda.bell@ualberta.ca 
LST could further exacerbate the deleterious effects this life stage can have on body composition ${ }^{(9)}$. In contrast, the accrual of LST has many benefits including increased metabolic rate ${ }^{(10)}$, reduction in inflammatory markers ${ }^{(11)}$ and decreased risk of age-related diseases such as sarcopenia ${ }^{(8,12)}$. Efforts to prevent LST decline should be initiated before menopause ${ }^{(13)}$ as previous research suggests that regular physical activity and adequate energy and protein intakes can attenuate losses in LST as women age ${ }^{(14-16)}$. The established functional ${ }^{(17)}$ and metabolic properties $^{(18)}$ of LST illustrate the importance of maintaining this body composition compartment for overall health.

Given the recent knowledge highlighting the beneficial effects of optimal LST on women's health, we aimed to characterise postpartum changes in LST. In addition, the commencement and/ or cessation of breast-feeding, coupled with subsequent changes in dietary intake and physical activity, could elicit changes in LST. Therefore, we also examined the effects of energy intake, physical activity and breast-feeding practices on change in LST between 3 and 9 months postpartum. We anticipated that fat and LST would be mobilised at different rates throughout the postpartum period based on a women's breast-feeding status, dietary intake and physical activity levels.

\section{Methods}

\section{Subjects}

This study was part of a longitudinal observational study investigating determinants of body weight and body composition during the postpartum period. Healthy postpartum women ( $n 53$ ) between 22 and 42 years of age from Alberta, Canada, were recruited using newspaper advertisements, flyers, mailings to specific listservs, local events with maternity or baby themes, community health clinics and word of mouth. All participants were at least 18 years of age, had a singleton term pregnancy (37-42 weeks) and were no more than 3 months postpartum at the time of enrolment. Women reported in good health, nonsmokers and not taking any medication which could affect their body composition or energy metabolism. This study was conducted according to the guidelines laid down in the Declaration of Helsinki and all procedures involving human subjects/patients were approved by the Health Research Ethics Board of the University of Alberta. Written informed consent was obtained from all subjects/patients before any data collection.

\section{Testing protocol and measurements}

Following recruitment, each participant completed a questionnaire and provided information including age, marital status, income, education, parity and birth delivery information. Participants also reported their prepregnancy weight and highest weight in pregnancy.

Participants visited the Human Nutrition Research Unit at the University of Alberta at 3 and 9 months postpartum. Women were instructed to arrive at the Unit between 07.00 and 08.00 hours in a fasted state. On arrival, anthropometrics were recorded (detailed below) and participants underwent a wholebody dual-energy X-ray absorptiometry (DXA) scan. A 3-d food diary, physical activity questionnaire and 3-d breast-feeding diary (including $1 \mathrm{~d}$ of infant test weighting) were then given to participants along with detailed instructions on how to complete them. This protocol was repeated at 9 months postpartum.

Anthropometrics and body composition. Postpartum body weight (Healthometer Professional Scale; Sunbeam Products Inc.) and standing height (235 Heightronic ${ }^{\mathrm{TM}}$, Concepts; QuickMedical) were measured to the nearest $0.1 \mathrm{~kg}$ and $0.1 \mathrm{~cm}$, respectively. Weight change was calculated as highest weight in pregnancy baby birth weight - current weight (measured). Body composition, including FM and LST, was measured using DXA (GE Medical Systems) and analysed with enCORE 9.20 software. Trunk, arm and leg values for FM and LST were obtained from subregion analysis of the whole-body scan. Composition of the android (area between the ribs and the pelvis, enclosed by the trunk region) and gynoid (hips, upper thighs, buttocks) regions was also obtained from subregion analysis ${ }^{(19)}$. LST was considered as the sum of body water, total body protein, carbohydrates, non-fat lipids, and soft tissue mineral, while fat-free mass (FFM) was calculated by adding the values of LST and bone mineral content provided by the DXA scans.

Dietary intake. Self-estimated information about recent food and beverage intake was collected using 3-d food diary that included two weekdays and one weekend day. Participants were trained by research staff on the level of detail needed to complete these records at the 3-month visit. Participants were instructed to self-report all food and drink (brand, estimated amount, cooking style, portion size) to the best of their ability using standard household measures (e.g. cups, tablespoons) to gauge food intake. Food diaries were reviewed by research staff for completeness and analysed for total energy content and macronutrient intake using Food Processor II (version 9.0; ESHA Research).

Physical activity. The Baecke physical activity questionnaire (BPAQ) was used to assess habitual physical activity levels. This is a sixteen-item questionnaire, with three categories of physical activity: 'at work', 'sport' and 'non-sport leisure' time. Scores for each of these categories (out of five) are calculated and summed for a total physical activity score out of fifteen. A higher score represents a higher level of physical activity. Details outlining the specific calculations used to score the BPAQ have been published elsewhere ${ }^{(20)}$. In addition, participation in mild, moderate and strenuous activities reported by participants was evaluated throughout the questionnaire.

Breast-feeding practices. Information on breast-feeding practices were obtained using a 3-d diary that included $1 \mathrm{~d}$ of infant test weighing. To obtain a measure of milk volume production, infants were weighed before and after each breast-feeding session for $24 \mathrm{~h}$ using an electronic baby scale with digital display (accuracy within $0.1 \mathrm{~g}$ and precision of $\pm 2 \cdot 0 \mathrm{~g}$ (BabyWeigh $^{\mathrm{TM}}$ II Scale; Medela)). Women were instructed not to change their infant's diaper between weighings within the same breast-feeding session. Milk volume production was calculated 
assuming $1 \mathrm{~g} / \mathrm{ml}$. During each test weighing day, as well as on two other days either before or after the test weighing, women recorded the frequency and duration of each feeding episode. Using information on volume of milk produced and the frequency and duration of breast-feeding sessions, energy expended in breast-feeding was calculated according to the WHO Human Energy requirements report ${ }^{(21)}$ and also expressed as a percentage of total energy expenditure (TEE).

Energy expenditure. TEE was estimated using the factorial method $^{(22)}$ from predicted resting energy expenditure combined with a physical activity level value of 1.4 , representing a low activity lifestyle as was previously found in postpartum women ${ }^{(23,24)}$. For lactating women, the calculated energy cost of breast-feeding, as outlined above, was added to the estimate of TEE.

\section{Statistical analysis}

GWG was calculated as the difference between highest weight in pregnancy minus prepregnancy weight. Women's adherence to the Institute of Medicine/Health Canada GWG guidelines ${ }^{(25)}$ was determined by categorising them as either having 'met' or 'exceeded' the GWG guidelines specific to their prepregnancy BMI. No participant gained weight at a level below their BMIspecific GWG guidelines. Energy intakes $(\mathrm{kJ} / \mathrm{d})$ were expressed as $\mathrm{kJ} / \mathrm{kg}$ and macronutrient intakes were expressed as $\mathrm{g} / \mathrm{kg}$ of body weight and as percentage of energy intake.

All data analyses were performed using SPSS for Windows version 15.0 (SPSS Inc.). Data are reported as means and standard deviations, and a $P$-value of $\leq 0.05$ was considered statistically significant. Paired $t$ tests were used to determine differences between prepregnancy and postpartum variables (at 3 and 9 months). Women were categorised according to whether they had gained or lost LST. Differences between these two groups' prepregnancy characteristics and postpartum dietary intake, physical activity scores and breast-feeding practices were evaluated using independent $t$ tests or Mann-Whitney $U$ tests for nonparametric data as appropriate. One-sample $t$ tests were used to determine whether changes in body composition across the postpartum period were significantly different from zero. This was an observational study, where the number of eligible women who completed the study at 3 and 9 months determined the sample size.

The relationships among energy intake, physical activity, energy expenditure, breast-feeding practices and changes in LST (as a continuous variable) were examined using linear regression. Univariate analyses were used to assess the association between LST change and dietary intake (total energy content and macronutrient intake (\%)), physical activity scores (total and sub scores) as well as breast-feeding variables (number of feeds per $d$, length of feeds and percentage of energy expended in breast-feeding). The significant independent variables that were entered into the regression analyses were continuous variables: energy intake $(\mathrm{kJ} / \mathrm{kg})$, fat intake (total energy content (\%)) and length of feeds per $\mathrm{d}$ at 3 months postpartum.

\section{Results}

\section{Group characteristics}

Of the fifty-three participants enrolled in the study, only four were lost to follow-up. One participant did not complete the 3-month postpartum test visit, while three (two due to subsequent pregnancy) did not return for the 9-month follow-up visit. In general, participants were college educated (80\%), married (90\%) and self-identified as Caucasian (88\%), Latin American (6\%) or Asian (6\%). Over half (57\%) of the participants were primiparous and most had had an uncomplicated vaginal delivery $(70 \%)$.

The prepregnancy and pregnancy anthropometrics, postpartum weight, dietary intake, physical activity scores and breast-feeding practices of the forty-nine women who completed the study and had data available at 3 and 9 months are presented in Table 1 . The majority of participants had a healthy BMI before pregnancy (57\%); however, overweight (25\%) and obese (18\%) participants were also part of the study. Approximately $49 \%$ met and $51 \%$ of participants exceeded their BMI-specific GWG guideline.

All women experienced a significant decline in weight over the postpartum measurement period (10.4 (sD 5.8) kg, $P<0 \cdot 001)$. As expected, average weight change was greater during the first 3 months postpartum $(-11.9$ (sD 3.4) kg) than between 3 and 9 months $(-2 \cdot 0(\mathrm{sD} 3 \cdot 8) \mathrm{kg})$. Although all women lost weight between delivery and 3 months postpartum, nine women gained weight $(2.8(\mathrm{sD} 3.5) \mathrm{kg}$ ) between 3 and 9 months postpartum. Average weight loss in those who continued to lose weight between 3 and 9 months postpartum ranged from $-2 \cdot 7$ to $-22 \cdot 0 \mathrm{~kg}$.

Women consumed 8996 (sD 2025) kJ/d (range: 5531$15431 \mathrm{~kJ} / \mathrm{d}$ ) and 8648 (sD 2113) kJ/d (range: 4381-12519 kJ/d) at 3 and 9 months, respectively. Total BPAQ activity scores at 3 months postpartum were $8 \cdot 1$ (SD 1.3) and were similar to scores at 9 months postpartum ( 8.0 (SD 1.8), $P=0.429$ ). In all, $80 \%$ of women ( $n$ 39) who participated in the study breast-fed for a minimum of 3 months, with $57 \%$ of those women continuing to breast-feed for up to 9 months postpartum. For those who had stopped breast-feeding by the end of the study, the average duration of breast-feeding was 189 (SD 91) d and ranged between 10 and $252 \mathrm{~d}$.

\section{Body composition changes between 3 and 9 months postpartum}

There was no significant change in average LST $(0.31$ (sD 1.2$) \mathrm{kg}, P=0.083)$ or FFM $(0 \cdot 26$ (sD 1.2$) \mathrm{kg}, P=0 \cdot 123)$ between 3 and 9 months postparum for the group as a whole, although there were significant reductions in total and regional FM (\%) between 3 and 9 months postpartum on a group level (Table 2). In addition, the amount of individual change in LST varied widely between women (Fig. 1). It was also evident that LST change did not follow the same trajectory in all women (Fig. 2); since between 3 and 9 months postpartum, twenty-nine women (59\%) accrued a significant amount of LST (1.1 (SD 0.7) kg, $P<0.001)$ and twenty women (41\%) lost LST ( -0.9 (sD 0.8$) \mathrm{kg}$, 
Table 1. Participant characteristics*

(Mean values and standard deviations; ranges and percentages)

\begin{tabular}{|c|c|c|c|}
\hline & Mean & SD & Range \\
\hline Age (years) & $32 \cdot 9$ & $3 \cdot 8$ & $22 \cdot 3-41 \cdot 5$ \\
\hline Height $(m)$ & 1.67 & 0.73 & $1.53-1.83$ \\
\hline Prepregnancy weight (kg) & 71.5 & $16 \cdot 2$ & $49.9-121.6$ \\
\hline Prepregnancy BMI $\left(\mathrm{kg} / \mathrm{m}^{2}\right) \dagger$ & $25 \cdot 7$ & $5 \cdot 3$ & $19 \cdot 5-41 \cdot 7$ \\
\hline Gestational weight gain $(\mathrm{kg})$ & $15 \cdot 1$ & $5 \cdot 1$ & $5 \cdot 0-27 \cdot 2$ \\
\hline \multicolumn{4}{|l|}{ Weight $(\mathrm{kg})$} \\
\hline After delivery $\ddagger$ & 83.1 & $15 \cdot 3$ & $61 \cdot 2-131.5$ \\
\hline 3 months & 74.4 & $15 \cdot 0$ & $54 \cdot 1-123 \cdot 5$ \\
\hline 9 months & $72 \cdot 7$ & $16 \cdot 9$ & $53 \cdot 4-120 \cdot 3$ \\
\hline \multicolumn{4}{|l|}{ Dietary intake } \\
\hline \multicolumn{4}{|l|}{ Energy intake $(\mathrm{kJ} / \mathrm{d})$} \\
\hline 3 months & 8996 & 2025 & $5531-15431$ \\
\hline 9 months & 8648 & 2113 & $4381-12519$ \\
\hline \multicolumn{4}{|l|}{ Energy intake $(\mathrm{kJ} / \mathrm{kg})$} \\
\hline 3 months & 126 & 38 & $63-213$ \\
\hline 9 months & 126 & 42 & 42-205 \\
\hline \multicolumn{4}{|l|}{ Carbohydrate (\%) } \\
\hline 3 months & 49 & 7 & $32-66$ \\
\hline 9 months & 45 & 7 & $24-55$ \\
\hline \multicolumn{4}{|l|}{ Protein $(\%)$} \\
\hline 3 months & 17 & 4 & $11-36$ \\
\hline 9 months & 18 & 5 & $12-40$ \\
\hline \multicolumn{4}{|l|}{ Fat $(\%)$} \\
\hline 3 months & 32 & 5 & $23-46$ \\
\hline 9 months & 36 & 6 & $22-52$ \\
\hline \multicolumn{4}{|l|}{ Physical activity scores§ } \\
\hline \multicolumn{4}{|l|}{ Total $(1-15)$} \\
\hline 3 months & $8 \cdot 2$ & $1 \cdot 2$ & $5 \cdot 9-10 \cdot 9$ \\
\hline 9 months & 8.3 & 1.2 & $5 \cdot 7-10 \cdot 9$ \\
\hline \multicolumn{4}{|l|}{ Sport (1-5) } \\
\hline 3 months & $2 \cdot 8$ & 0.9 & $1.0-4.5$ \\
\hline 9 months & $2 \cdot 8$ & 0.9 & $1.3-4.5$ \\
\hline \multicolumn{4}{|l|}{ Leisure (1-5) } \\
\hline 3 months & $2 \cdot 8$ & 0.4 & $1.6-3.7$ \\
\hline 9 months & $2 \cdot 8$ & 0.5 & $1.9-3.6$ \\
\hline \multicolumn{4}{|l|}{ Work $(1-5)$} \\
\hline 3 months & $2 \cdot 7$ & 0.3 & $1.9-3.6$ \\
\hline 9 months & $2 \cdot 8$ & 0.4 & $1.5-3.8$ \\
\hline \multicolumn{4}{|l|}{ Breast-feeding practices\|ll } \\
\hline \multicolumn{4}{|l|}{ Number of feeds/d } \\
\hline 3 months & 9 & 3 & $3-15$ \\
\hline 9 months & 7 & 3 & $2-15$ \\
\hline \multicolumn{4}{|l|}{ Total time feeding $(\mathrm{min} / \mathrm{d})$} \\
\hline 3 months & 155 & 72 & $60-358$ \\
\hline 9 months & 94 & 70 & 13-309 \\
\hline \multicolumn{4}{|c|}{ Energy expended breast-feeding $(\mathrm{kJ} / \mathrm{d})$} \\
\hline 3 months & 2741 & 895 & $837-5213$ \\
\hline 9 months & 1946 & 799 & $226-3163$ \\
\hline \multicolumn{4}{|c|}{ TEE expended breast-feeding (\%) } \\
\hline 3 months & 22 & 6 & $9-36$ \\
\hline 9 months & 16 & 6 & $2-26$ \\
\hline
\end{tabular}

TEE, total energy expenditure.

* Prepregnancy and pregnancy anthropometrics, postpartum weight, dietary intake, physical activity and breast-feeding practices ( $n$ 49). $\dagger$ Self-reported prepregnancy weight and height measured at 3 months postpartum were used to calculate prepregnancy BMI.

¥ Weight after delivery was calculated as the highest weight in pregnancy minus baby birth weight.

$\S$ The Baecke total physical activity score was calculated by summing the activity components (sport, leisure, work) scores to give a total score out of 15 . II Number of women breast-feeding at 3 and 9 months was 39 and 28 , respectively.

$P<0.001$ ) (Table 3). The absolute difference between groups in LST gain and loss was significant for each region examined, respectively: arms (0.0 (SD 0.0) $v$. $-0.1(\mathrm{SD} 0.2) \mathrm{kg}, P=0.004)$, legs $(0.3(\mathrm{sD} 0.3) v .-0.2(\mathrm{sD} 0.4) \mathrm{kg}, P<0.001)$, trunk (0.7 (SD 0.6) $v$. -0.6 (sD 0.7$) \mathrm{kg}, \quad P<0.001)$, android (0.1 (sD 0.1$) \quad v$. -0.1 $(\mathrm{sD} 0 \cdot 1) \mathrm{kg}, P<0 \cdot 001)$ and gynoid $(0 \cdot 2$ (sD $0 \cdot 2) v \cdot-0 \cdot 1(\mathrm{sD} 0 \cdot 2) \mathrm{kg}$, $P<0.001)$.
Despite differences in LST change, body weight was not significantly different at 3 or 9 months postpartum between women who gained LST or lost LST (Table 3). Interestingly, total FM decreased significantly in women who gained and those who lost LST ( $-2 \cdot 4$ (sD 4.2$) \mathrm{kg}, P=0.005$ and $-2 \cdot 1$ (sD 2.4) kg, $P=0.001 \mathrm{FM}$, respectively). Age, height, prepregnancy weight, prepregnancy BMI, GWG and highest weight in pregnancy did not differ 
Table 2. Body composition (total and regional) at 3 and 9 months postpartum ( $n$ 49) (Mean values and standard deviations)

\begin{tabular}{|c|c|c|c|c|c|}
\hline & \multicolumn{2}{|c|}{3 months postpartum } & \multicolumn{2}{|c|}{9 months postpartum } & \multirow[b]{2}{*}{$P$} \\
\hline & Mean & SD & Mean & SD & \\
\hline Lean soft tissue (kg) & $42 \cdot 2$ & 4.9 & 42.5 & $5 \cdot 0$ & 0.082 \\
\hline Fat-free mass $(\mathrm{kg})$ & 44.9 & $5 \cdot 3$ & $45 \cdot 2$ & $5 \cdot 3$ & 0.123 \\
\hline Fat mass $(\mathrm{kg})$ & 29.8 & $12 \cdot 2$ & $27 \cdot 5$ & 13.5 & $<0.001$ \\
\hline Total percentage fat mass & 38.5 & 8.4 & $36 \cdot 1$ & 9.4 & 0.001 \\
\hline Arms percentage fat mass & 33.8 & $9 \cdot 4$ & $32 \cdot 3$ & 10.5 & $<0.001$ \\
\hline Legs percentage fat mass & $41 \cdot 2$ & 8.2 & $38 \cdot 7$ & $9 \cdot 0$ & $<0.001$ \\
\hline Trunk percentage fat mass & $39 \cdot 8$ & $9 \cdot 2$ & $37 \cdot 1$ & $10 \cdot 3$ & $<0.001$ \\
\hline Android region percentage fat mass & 44.6 & 9.9 & 41.8 & 11.6 & $<0.001$ \\
\hline Gynoid region percentage fat mass & $47 \cdot 2$ & $6 \cdot 7$ & 44.9 & 7.5 & $<0.001$ \\
\hline
\end{tabular}

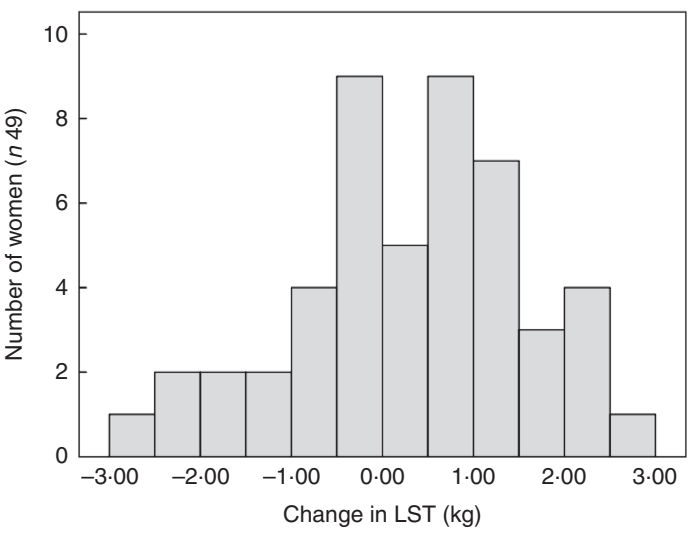

Fig. 1. Histogram of the change in lean soft tissue (LST) between 3 and 9 months postpartum.

between groups of women who gained or lost LST between 3 and 9 months postpartum. In addition, those who gained or lost LST also did not differ with respect to adherence to GWG guidelines (gained LST met: 45\%; exceeded: 55\%; lost LST met: 55\%; exceeded: $45 \%$ ) or parity (gained LST: primiparous $52 \%$, multiparous $48 \%$; lost LST: primiparous $55 \%$ and multiparous $45 \%$ ).

Energy intake $(\mathrm{kJ} / \mathrm{kg})$ and $\% \mathrm{~kJ}$ from fat at 3 months postpartum were higher in women who gained compared with those who lost LST (Table 3). Through a more in-depth analysis, we observed that women who gained LST had a higher relative intake of saturated fat than those who lost LST (12.3 (SD 2.6) and $9 \cdot 7$ (SD 2.5 ) \%, respectively); no differences in mono- or polyunsaturated fat intake were reported. At 9 months postpartum, no differences in energy, fat intake or physical activity were observed; however, women who gained LST reported breastfeeding their infants more frequently and for a longer period of time per $\mathrm{d}$. While not significant, a higher percentage of women who gained LST participated in moderate and strenuous physical activity at 3 and 9 months postpartum in comparison with women who lost LST (55 v. $21 \%, P=0.625$ and 40 v. $23 \%$, $P=0 \cdot 322$, respectively).

\section{Relationship between behavioural characteristics and changes in lean soft tissue}

Linear regression was used to examine whether dietary intake, physical activity or breast-feeding practices were

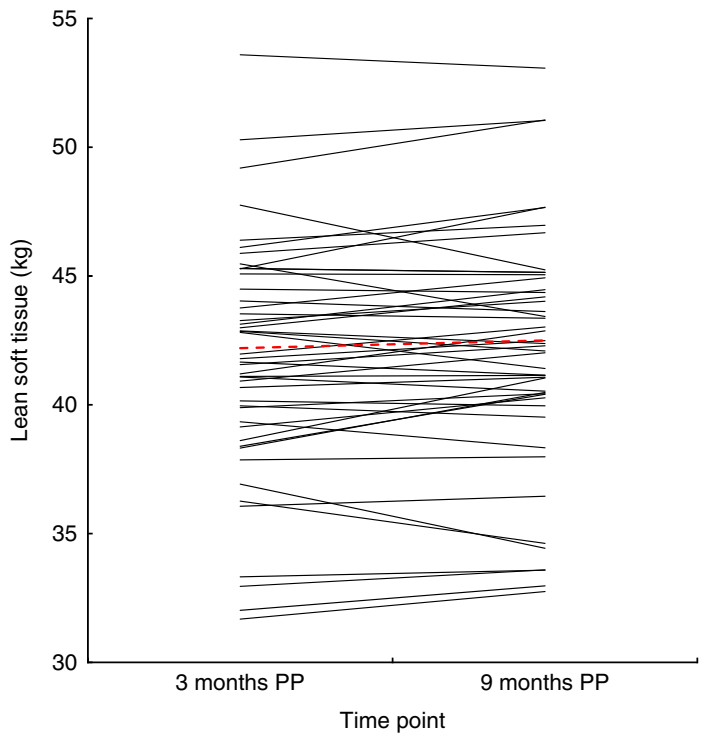

Fig. 2. Change in lean soft tissue between 3 and 9 months postpartum (PP). - Individual changes in lean soft tissue between 3 and 9 months PP. ----, Average lean soft tissue change for the group as a whole $(0.3$ (SD $1.2) \mathrm{kg}$, range: -2.5 to $2.5 \mathrm{~kg}$ ).

associated with changes in LST between 3 and 9 months postpartum. Energy intake, fat intake (\%) and number of feeds per $\mathrm{d}$ at 3 months postpartum were entered into the model (Table 4) as these variables were significantly associated with LST in the univariate analyses. Energy intake and number of breast-feeds per d at 3 months postpartum were not associated with an increase in LST. However, higher dietary fat intake (\% kJ) at 3 months was significantly associated with an increase in the likelihood of gaining LST over the postpartum period.

\section{Discussion}

Results from this study highlight the large variability in LST changes that occur in postpartum women. Although the trajectory of FM and bone mineral density changes in the postpartum period have previously been explored, changes in LST have not been well documented. The retention and loss of LST have been examined by only few studies in this population and often as a secondary measure of body composition ${ }^{(26,27)}$. 
Table 3. Anthropometric characteristics, dietary intake, physical activity and breast-feeding practices of women who gained or lost lean soft tissue between 3 and 9 months postpartum†

(Mean values and standard deviations)

\begin{tabular}{|c|c|c|c|c|}
\hline & \multicolumn{2}{|c|}{$\begin{array}{l}\text { Gained lean soft tissue } \\
(n 29)\end{array}$} & \multicolumn{2}{|c|}{$\begin{array}{l}\text { Lost lean soft tissue } \\
\qquad(n 20)\end{array}$} \\
\hline & Mean & SD & Mean & SD \\
\hline \multicolumn{5}{|c|}{ Prepregnancy and pregnancy anthropometrics } \\
\hline Age (years) & $32 \cdot 7$ & 3.2 & $33 \cdot 2$ & 4.5 \\
\hline Height $(m)$ & 1.67 & 0.72 & 1.68 & 0.75 \\
\hline Prepregnancy weight $(\mathrm{kg})$ & 68.4 & 14.7 & $76 \cdot 0$ & $17 \cdot 7$ \\
\hline Prepregnancy BMI $¥\left(\mathrm{~kg} / \mathrm{m}^{2}\right)$ & $24 \cdot 9$ & 4.7 & $27 \cdot 0$ & $6 \cdot 0$ \\
\hline Gestational weight gain (kg) & $16 \cdot 1$ & $5 \cdot 1$ & $13 \cdot 6$ & $5 \cdot 8$ \\
\hline Excess gestational weight gain $(\mathrm{kg})$ & 3.0 & 4.3 & $2 \cdot 5$ & 3.7 \\
\hline Weight after delivery§ $(\mathrm{kg})$ & $81 \cdot 0$ & 14.7 & $86 \cdot 2$ & $16 \cdot 0$ \\
\hline \multicolumn{5}{|l|}{ Postpartum weight $(\mathrm{kg})$} \\
\hline 3 months & $72 \cdot 1$ & $15 \cdot 1$ & $78 \cdot 2$ & $16 \cdot 4$ \\
\hline 9 months & $70 \cdot 9$ & $16 \cdot 9$ & $75 \cdot 3$ & $16 \cdot 9$ \\
\hline \multicolumn{5}{|l|}{ Dietary intake } \\
\hline \multicolumn{5}{|l|}{ Energy intake (kJ/kg) } \\
\hline 3 months & $134^{\star}$ & 32 & 109 & 33 \\
\hline 9 months & 134 & 32 & 117 & 32 \\
\hline \multicolumn{5}{|l|}{ Carbohydrate (\%) } \\
\hline 3 months & 48 & 7 & 52 & 7 \\
\hline 9 months & 45 & 7 & 46 & 5 \\
\hline \multicolumn{5}{|l|}{ Protein $(\%)$} \\
\hline 3 months & 17 & 4 & 18 & 5 \\
\hline 9 months & 18 & 6 & 18 & 4 \\
\hline \multicolumn{5}{|l|}{ Fat $(\%)$} \\
\hline 3 months & $34^{*}$ & 5 & 30 & 4 \\
\hline 9 months & 35 & 6 & 36 & 5 \\
\hline \multicolumn{5}{|l|}{ Physical activity scores\| } \\
\hline \multicolumn{5}{|l|}{ Total $(1-15)$} \\
\hline 3 months & $8 \cdot 3$ & $1 \cdot 2$ & $8 \cdot 1$ & 1.4 \\
\hline 9 months & 8.5 & 1.2 & 8.2 & 1.2 \\
\hline \multicolumn{5}{|l|}{ Sport (1-5) } \\
\hline 3 months & $2 \cdot 8$ & 0.9 & $2 \cdot 7$ & 0.9 \\
\hline 9 months & $2 \cdot 9$ & 0.9 & $2 \cdot 7$ & 0.8 \\
\hline \multicolumn{5}{|l|}{ Leisure $(1-5)$} \\
\hline 3 months & $2 \cdot 8$ & 0.4 & $2 \cdot 8$ & 0.5 \\
\hline 9 months & $2 \cdot 7$ & 0.5 & $2 \cdot 8$ & 0.3 \\
\hline \multicolumn{5}{|l|}{ Work (1-5) } \\
\hline 3 months & $2 \cdot 7$ & 0.3 & $2 \cdot 7$ & 0.4 \\
\hline 9 months & $2 \cdot 9$ & 0.5 & $2 \cdot 7$ & 0.4 \\
\hline \multicolumn{5}{|l|}{ Breast-feeding practices $\uparrow$} \\
\hline \multicolumn{5}{|l|}{ Number of feeds/d } \\
\hline 3 months & 9 & 3 & 8 & 2 \\
\hline 9 months & $8^{*}$ & 3 & 5 & 1 \\
\hline \multicolumn{5}{|l|}{ Total time feeding $(\mathrm{min} / \mathrm{d})$} \\
\hline 3 months & 169 & 72 & 130 & 67 \\
\hline 9 months & $115^{\star}$ & 78 & 59 & 34 \\
\hline \multicolumn{5}{|l|}{ Energy expended breast-feeding $(\mathrm{kJ} / \mathrm{d})$} \\
\hline 3 months & 2628 & 757 & 2941 & 1100 \\
\hline 9 months & 2096 & 678 & 1690 & 958 \\
\hline \multicolumn{5}{|c|}{ Total energy expended breast-feeding (\%) } \\
\hline 3 months & 21 & 6 & 22 & 7 \\
\hline 9 months & 18 & 5 & 14 & 7 \\
\hline
\end{tabular}

* Significant difference between groups, $P<0.05$.

† The numbers of women breast-feeding among those who gained lean soft tissue and those that lost lean soft tissue were $n 25$ at 3 months, $n 14$ at 9 months, and $n 17$ at 3 months and $n 11$ at 9 months, respectively.

$\ddagger$ Self-reported prepregnancy weight and height measured at 3 months postpartum were used to calculate prepregnancy BMI.

§Weight after delivery was calculated as the highest weight in pregnancy minus baby birth weight.

\| The Baecke total physical activity score was calculated by summing the activity components (sport, leisure, work) scores to give a total score out of 15.

If Number of women breast-feeding at 3 and 9 months was 39 and 28, respectively.

While changes in weight and FM are clearly important, there is a growing appreciation for the extent to which LST is a strong predictor of health ${ }^{(17)}$. Pregnancy and postpartum are important life stages, characterised by significant metabolic and physiological changes and adaptations. It is important to examine the many changes in all components of body composition to further our understanding of how these are coordinated and can contribute to future health and/or disease risk for the mother.

On a group level, women lost weight over the postpartum period, most of which was from the FM compartment. These 
Table 4. Linear regression: postpartum factors associated with changes in lean soft tissue in a multivariate analysis

( $\beta$-Coefficients and standard errors)

\begin{tabular}{lrcrc}
\hline Independent variables & $\beta$ & SE & \multicolumn{1}{c}{$95 \% \mathrm{Cl}$} & $P$ \\
\hline Energy intake at 3 months (kJ/d) & 0.001 & 0.00 & $0.00,001$ & 0.141 \\
Fat intake $(\% \mathrm{~kJ})$ at 3 months & 0.113 & 0.04 & $0.04,0.19$ & 0.005 \\
Number of feeds/d at 3 months & -0.127 & 0.08 & $-0.28,0.02$ & 0.096 \\
\hline
\end{tabular}

results are consistent with Hatsu et $a l .{ }^{(28)}$, who reported significant changes (loss) in maternal weight and percent body fat in exclusively breast-feeding ( $n$ 17) and mixed feeding ( $n$ 7) women aged 19-24 years. However, on further examination of body composition change overtime in our study, it became evident that not all women followed the same pattern of LST change. Approximately $60 \%$ of the women studied experienced a significant increase in LST, while the others lost LST over the postpartum period. In studies assessing nutritional status and body composition in clinical cohorts, a change in $1 \mathrm{~kg}$ of LST is considered physiologically significant ${ }^{(29)}$. Here, we found $30 \%$ of women had over a $1 \mathrm{~kg}$ increase in LST, while some women (15\%) had lost over $1 \mathrm{~kg}$ of LST. In order to understand and examine the potential health effects these changes in LST may have, and how a woman's body composition changes over their lifespan, long-term follow-up throughout postpartum is needed.

Gain in LST at 9 months postpartum was associated with more frequent and longer episodes of breast-feeding at 9 months and higher energy and fat intakes at 3 months. Lactation is thought to stimulate changes in maternal body composition, via mobilising FM however, its influence on changes in LST is yet to be established. Physiological mechanisms related to lactation that could increase LST need further study, but hormones such as oxytocin and prolactin are likely contributors ${ }^{(30)}$. A growing body of evidence suggests that oxytocin is important in regulating energy balance ${ }^{(31)}$. Furthermore, in a study of female athletes, Lawson et al. ${ }^{(32)}$, noted that oxytocin secretion was positively associated with resting energy expenditure in athletes but not in non-athletes and suggested that oxytocin may have particular importance in energy-deficient states; this could perhaps, for some women, be throughout lactation. The extent to which this contributes to body composition changes in postpartum women deserves further study. In addition, other hormones that could be contributing to body composition changes include testosterone and oestrogen. Variation in these hormones during the postpartum period could inhibit some women from gaining LST (e.g. if testosterone was low and oestrogen was high) or could attenuate the loss of LST if testosterone was high and oestrogen was relatively high. Unfortunately, these hormones were not measured in this study, and inferences on the effects they have on changes in LST throughout postpartum cannot be made.

The observation that higher energy intakes and higher fat intakes at 3 months postpartum is associated with LST gain is unexpected. This result could be attributed to how we explored fat intake both as a percentage of overall energetic intake and as per kg of body weight. Perhaps by expressing fat intake relative to body weight, the relationship between fat intake and LST accrual was highlighted. Previous studies may have missed this when only controlling for energy intake. Speculating as to why a higher fat intake could have contributed to increase LST, we looked at what prior studies had reported on the link between fat intake and LST.

One previous study ${ }^{(33)}$ found that LST may be accrued throughout lactation in well-nourished women and linked this to higher energy and protein intakes in these women ${ }^{(33)}$. These authors suggested that diets high in energy and protein may preserve LST from catabolism by meeting the metabolic needs for milk protein production in the mammary glands. Furthermore, a study by Noreen et al. ${ }^{(34)}$ documented that in healthy adults, polyunsaturated fat intake may promote muscle gain. In fact, long-chain fatty acids have anabolic properties which could stimulate muscle synthesis in healthy adults ${ }^{(35)}$. However, no difference in polyunsaturated fat intake between women who gained LST and those who lost LST was observed in this cohort. Furthermore, fat intake has also been documented to induce sparing of body nitrogen by a reduction in amino acid oxidation in energy-deficient state ${ }^{(36)}$. Any or all of these three effects may have been occurring in some women and could contribute to accrual of LST. These observations deserve additional follow-up.

Increases in physical activity may also promote increases in LST although this is not well studied in postpartum women. In this study, physical activity was not associated with changes in LST and sport activity scores were not different at 3 and 9 months postpartum among women who gained or lost LST. While more women who gained LST reported engaging in moderate to vigorous physical activities at 3 and 9 months postpartum, differences between groups were not significant. The small effect size, relatively small sample size and sensitivity of the questionnaire could all contribute to the lack of statistical significance. It is possible that the type of physical activity in addition to the amount is more important in eliciting changes in LST. Resistance exercises have been found to elicit gains in LST in healthy non-pregnant, non-lactating women ${ }^{(37)}$, and Sims et al. ${ }^{(38)}$, reported that resistance training is needed to prevent loss in LST as women age. Details about the type of exercises performed (i.e. strength, aerobic, resistance) was not collected in our study but should be examined in more detail in future studies ${ }^{(39,40)}$. Determining the types and amount of physical activity that could support the accrual and preservation of LST during the postpartum period may be helpful in refining guidelines and guiding intervention study design.

To the authors' knowledge, this was the first study to assess changes in LST during the postpartum period using a sophisticated method of body composition assessment and detailed information on dietary intake, physical activity and breastfeeding practices in a cohort of well-nourished Western women. As with other studies, the fact that participants were predominately Caucasian, highly educated and experiencing their first or second pregnancy could limit the generalisability of our results. Women who have experienced multiple pregnancies, or from other ethnic groups or socio-economic backgrounds may have higher variation in health behaviours. It is unfortunate that our assessments could not begin earlier and collect data more frequently in the postpartum period. Data collected at more frequent intervals could help to identify 
differences in LST across this period, particularly at the time that many women cease lactation. There are well-known difficulties with assessing physical activity using self-reports ${ }^{(41)}$. The use of objective measures of physical activity was beyond the scope and resources of this study but should be considered in future studies. Another limitation worth commenting on is that total body water was not assessed. Hydration changes have been reported to fluctuate throughout pregnancy and during lactation. The accuracy of DXA may be affected by hydration status as the analysis program assumes a constant and uniform FFM hydration and large changes in hydration (higher than 5\%) can change the attenuation of fat-free soft tissue ${ }^{(42)}$ which could cause an overestimation of the LST compartment. While it has been documented that changes in hydration status (primarily an increase in extracellular fluid) occur during pregnancy ${ }^{(2,43)}$, very little is known about hydration status and its impact on the measurements of LST during the postpartum period. One previous report ${ }^{(44)}$ has shown that the hydration of FFM was elevated at 2 weeks postpartum, and differed between lactating and non-lactating women. However, a similar study showed that by 3 months postpartum, the relative composition and hydration of the FFM had returned to within the normal range and no differences were seen between lactating and non-lactating women ${ }^{(44)}$. Based on this, it is unlikely that hydration status had a major impact on measurement of LST in the current study.

Difficulties in comparing our findings with published literature arise from a lack of data reporting changes in LST throughout the postpartum period. As mentioned previously, small changes in LST can have significant physiological effects on health. Our research has illustrated that LST change throughout the postpartum period is highly variable, with some women having over a $1 \mathrm{~kg}$ increase or decrease in LST. In addition, our modest sample size in this study ( $n$ 49) may have played a role in limiting the significance of some of the statistical comparisons conducted. A post hoc power analysis revealed that on the basis of the mean and between-group comparison effect size observed in the present study ( $d=0 \cdot 15)$, an $n$ of approximately 620 would be needed to obtain statistical power at the recommended 0.80 level. Recruiting this many women at 3 months postpartum to perform multiple body composition tests, complete $24 \mathrm{~h}$ weigh-reweigh breastfeeding diaries, and collect data on food intake and physical activity levels was unfeasible, and beyond the scope of this present observational study.

It is important to note that DXA body composition scans are not without error. A recent study investigating the least significant change when measuring body composition via DXA showed that DXA scans for whole-body LST measured $<1 \%$ $\mathrm{CV}^{(45)}$. However, given the functional and metabolic importance of LST, this still highlights the need to further explore the complex physiological and behavioural variables associated with changes in LST over the pregnancy-postpartum cycle as a whole. Larger studies with detailed assessments of body composition along with behavioural and physiological factors associated with energy balance would help determine the influences and factors which drive changes in LST over the postpartum period.

The findings of this study suggest that dietary intake early in the postpartum period and frequent and longer episodes of breast-feeding at 9 months postpartum contributes to improvements in postpartum LST. Given what we know about the importance of LST on health, more thorough elucidation of the specific physiological and behavioural determinants of LST could help guide effective interventions and improve women's health during and after the postpartum period.

\section{Acknowledgements}

The authors are sincerely grateful to all study participants, as well as students and staff at the Human Nutrition Research Unit who helped facilitate the project (Emmanuel Guigard, Stephanie Ramage and Adele Gagnon).

The ENRICH Project is funded through an Alberta Innovates Health Solutions (AIHS), Collaborative Research and Innovation Opportunity team grant (RES0017751). S. A. E. was supported by an AIHS postdoctoral fellowship. L. C. R. P. is supported by a Vanier Graduate Student Scholarship. The funders had no role in the design, analysis or writing of this article.

The authors' responsibilities were as follows: R. C. B., L. J. M. and C. M. P. designed the research project; S. A. E. and L. C. R. P. conducted the research; S. A. E. and C. M. P. analysed the data; S. A. E. and R. C. B. wrote the manuscript and had primary responsibility for the final content of the manuscript; and all authors read and approved the final manuscript.

The authors declare that there are no conflicts of interest.

\section{References}

1. Gilmore LA, Klempel-Donchenko M \& Redman LM (2015) Pregnancy as a window to future health: excessive gestational weight gain and obesity. Semin Perinatol 39, 296-303.

2. Widen EM \& Gallagher D (2014) Body composition changes in pregnancy: measurement, predictors and outcomes. Eur $J$ Clin Nutr 68, 643-652.

3. Cho GJ, Yoon HJ, Kim E-J, et al. (2011) Postpartum changes in body composition. Obesity 19, 2425-2428.

4. Gunderson EP (2009) Childbearing and obesity in women: weight before, during, and after pregnancy. Obstet Gynecol Clin North Am 36, 317-332, ix.

5. Neville CE, McKinley MC, Holmes VA, et al. (2014) The relationship between breastfeeding and postpartum weight change-a systematic review and critical evaluation. Int $J$ Obes 38, $577-590$

6. Pietrobelli A, Faith MS, Wang J, et al. (2002) Association of lean tissue and fat mass with bone mineral content in children and adolescents. Obes Res 10, 56-60.

7. Amarya S, Singh K \& Sabharwal M (2015) Changes during aging and their association with malnutrition. J Clin Gerontol Geriatr 6, 78-84.

8. Wolfe RR (2006) The underappreciated role of muscle in health and disease. Am J Clin Nutr 84, 475-482.

9. Heymsfield SB, Gallagher D, Poehlman ET, et al. (1994) Menopausal changes in body composition and energy expenditure. Exp Gerontol 29, 377-389.

10. Zurlo F, Larson K, Bogardus C, et al. (1990) Skeletal muscle metabolism is a major determinant of resting energy expenditure. J Clin Invest 86, 1423-1427.

11. Woods JA, Wilund KR, Martin SA, et al. (2012) Exercise, inflammation and aging. Aging Dis 3, 130-140. 
12. Santanasto AJ, Goodpaster BH, Kritchevsky SB, et al. (2016) Body composition remodeling and mortality: the health aging and body composition study. J Gerontol A Biol Sci Med Sci $\mathbf{7 2}$, 513-519.

13. Nishiguchi S, Yamada M, Kajiwara Y, et al. (2014) Effect of physical activity at midlife on skeletal muscle mass in old age in community-dwelling older women: a cross-sectional study. J Clin Gerontol Geriatr 5, 18-22.

14. Krieger JW, Sitren HS, Daniels MJ, et al. (2006) Effects of variation in protein and carbohydrate intake on body mass and composition during energy restriction: a metaregression 1. Am J Clin Nutr 83, 260-274.

15. Maltais ML, Desroches J \& Dionne IJ (2009) Changes in muscle mass and strength after menopause. JMusculoskelet Neuronal Interact 9, 186-197.

16. Diniz TA, Christofaro DGD, dos Santos VR, et al. (2015) Practice of moderate physical activity can attenuate the loss of lean body mass in menopausal women. Eur J Obstet Gynecol Reprod Biol 11, 151-159.

17. St-Onge MP (2005) Relationship between body composition changes and changes in physical function and metabolic risk factors in aging. Curr Opin Clin Nutr Metab Care 8, 523-528.

18. Muller MJ, Bosy-Westphal A, Kutzner D, et al. (2003) Metabolically active components of fat free mass (FFM) and resting energy expenditure (REE) in humans. Forum Nutr $\mathbf{5 6}$, 301-303.

19. Petak S, Barbu CG, Yu EW, et al. (2013) The official positions of the international society for clinical densitometry: body composition analysis reporting. J Clin Densitom 16, 508-519.

20. Baecke JA, Burema J \& Frijters J (1982) A short questionnaire for the measurement of habitual physical activity in epidemiological studies. Am J Clin Nutr 36, 936-942.

21. Food and Agriculture Organization (2001) Energy Requirements of Lactation. Human Energy Requirements: Report of a Joint FAO/WHO/UNU Expert Consultation. Rome: Food and Agriculture Organization of the United Nations.

22. Institute of Medicine (2002) Physical Activity. Dietary Reference Intakes for Energy, Carbohydrate, Fiber, Fat, Fatty Acids, Cholesterol, Protein and Amino Acids (Macronutrients). Washington, DC: Institute of Medicine/Food and Nutrition Board.

23. Blum JW, Beaudoin CM \& Caton-Lemos L (2004) Physical activity patterns and maternal well-being in postpartum women. Matern Child Health J 8, 163-169.

24. Durham HA, Morey MC, Lovelady CA, et al. (2011) Postpartum physical activity in overweight and obese women. J Phys Act Health 8, 988-993.

25. Health Canada (2010) Prenatal Nutrition Guidelines for Health Professionals: Gestational Weight Gain. Ottawa: Health Canada.

26. AbuSabha R \& Greene G (1998) Body weight, body composition, and energy intake changes in breastfeeding mothers. J Hum Lact 14, 119-124.

27. Møller UK, við Streym S, Mosekilde L, et al. (2012) Changes in bone mineral density and body composition during pregnancy and postpartum. A controlled cohort study. Osteoporos Int 23, 1213-1223.

28. Hatsu IE, McDougald DM \& Anderson AK (2008) Effect of infant feeding on maternal body composition. Int Breastfeed J 3, 18.

29. Prado CMM, Bekaii-Saab T, Doyle LA, et al. (2012) Skeletal muscle anabolism is a side effect of therapy with the MEK inhibitor: selumetinib in patients with cholangiocarcinoma. Br J Cancer 106, 1583-1586.

30. Blevins JE \& Baskin DG (2015) Translational and therapeutic potential of oxytocin as an anti-obesity strategy: insights from rodents, nonhuman primates and humans. Physiol Behav 152, 438-449.

31. Ben-Jonathan N \& Hugo E (2015) Prolactin (PRL) in adipose tissue: regulation and functions. Adv Exp Med Biol 846, 1-35.

32. Lawson EA, Ackerman KE, Slattery M, et al. (2014) Oxytocin secretion is related to measures of energy homeostasis in young amenorrheic athletes. J Clin Endocrinol Metab 99, E881-E885.

33. Motil KJ, Sheng HP, Kertz BL, et al. (1998) Lean body mass of well-nourished women is preserved during lactation. $\mathrm{Am} \mathrm{J}$ Clin Nutr 67, 292-300

34. Noreen EE, Sass MJ, Crowe ML, et al. (2010) Effects of supplemental fish oil on resting metabolic rate, body composition, and salivary cortisol in healthy adults. J Int Soc Sports Nutr 7, $1-7$.

35. Smith GI, Atherton P, Reeds DN, et al. (2011) Omega-3 polyunsaturated fatty acids augment the muscle protein anabolic response to hyperaminoacidemia-hyperinsulinemia in healthy young and middle aged men and women. Clin Sci 121, 267-278

36. Vazquez JA, Paul HS \& Adibi SA (1988) Regulation of leucine catabolism by caloric sources. Role of glucose and lipid in nitrogen sparing during nitrogen deprivation. J Clin Invest $\mathbf{8 2}$, $1606-1613$

37. Chilibeck DP, Calder WA, Sale GD, et al. (1997) A comparison of strength and muscle mass increases during resistance training in young women. EurJ Appl Physiol Occup Physiol 1, 170-175.

38. Sims ST, Kubo J, Desai M, et al. (2013) Changes in physical activity and body composition in postmenopausal women over time. Med Sci Sports Exerc 45, 1486-1492.

39. Dewey KG, Lovelady CA, Nommsen-Rivers LA, et al. (1994) A randomized study of the effects of aerobic exercise by lactating women on breast-milk volume and composition. $N$ Engl J Med 330, 449-453.

40. Larson-Meyer DE (2002) Effect of postpartum exercise on mothers and their offspring: a review of the literature. Obes Res 10, 841-853.

41. Pettee KK, Storti KL, Ainsworth BE, et al. (2008) Measurement of physical activity and inactivity in epidemiologic studies. In Epidemiologic Methods in Physical Activity Studies, September 2009 ed. [I-M Lee, editor]. New York: Oxford University Press, Inc.

42. Roubenoff R, Kehayias JJ, Dawson-Hughes B, et al. (1993) Use of dual-energy X-ray absorptiometry in body-composition studies: not yet a "gold standard". Am J Clin Nutr 58, 589-591.

43. Lof M \& Forsum E (2004) Hydration of fat-free mass in healthy women with special reference to the effect of pregnancy. $A m J$ Clin Nutr 80, 960-965.

44. Butte NF, Hopkinson JM, Ellis KJ, et al. (1997) Changes in fat-free mass and fat mass in postpartum women: a comparison of body composition models. Int J Obes Relat Metab Disord 21, 874-880.

45. Najm N, Popp C, Traylor D, et al. (2015) Least significant change of body composition and bone mineral density measured by dual energy X-ray absorptiometry. FASEB J 29, 1 Suppl., 632.8. 